60-61| 2018

La culture dans l'enseignement du français langue étrangère: conceptions théoriques, programmes et manuels auX $\mathrm{XIX}^{\mathrm{e}}$ et $\mathrm{XX}^{\mathrm{e}}$ siècles

\title{
La culture dans la littérature française traduite ou enseignée : une contribution à la modernisation de la Turquie (XIX $\mathrm{XXX}^{\mathrm{e}}$ siècles)
}

Culture in French literature translated or taught: a contribution to the modernisation of Turkey (19th-20th centuries)

Arzu Etensel Ildem

\section{(2) OpenEdition \\ 1 Journals}

Édition électronique

URL : https://journals.openedition.org/dhfles/5519

DOI : $10.4000 /$ dhfles.5519

ISSN : 2221-4038

Éditeur

Société Internationale pour l'Histoire du Français Langue Étrangère ou Seconde

Édition imprimée

Date de publication : 1 janvier 2018

Pagination : 261-271

ISSN : 0992-7654

Référence électronique

Arzu Etensel Ildem, « La culture dans la littérature française traduite ou enseignée : une contribution à la modernisation de la Turquie (XIXe-XXe siècles) », Documents pour l'histoire du français langue étrangère ou seconde [En ligne], 60-61 | 2018, mis en ligne le 30 juin 2019, consulté le 25 mars 2023. URL : http://journals.openedition.org/dhfles/5519; DOI : https://doi.org/10.4000/dhfles.5519 


\title{
La culture dans la littérature française traduite ou enseignée : une contribution à la modernisation de la Turquie (XIX ${ }^{\mathrm{e}}-\mathrm{XX}^{\mathrm{e}}$ siècles)
}

\author{
Culture in French literature translated or taught: a contribution to the \\ modernisation of Turkey (19th-20th centuries)
}

Arzu Etensel Ildem

FR

21 décembre 2018

31 juin 2019

4 Grâce aux articles parus dans Documents l'aventure de la langue française dans l'Empire ottoman et dans la République de Turquie est déjà bien connue. Sans tomber dans la répétition nous allons revoir brièvement les grandes lignes de l'apparition et du développement de la langue française en Turquie pour montrer l'importance de l'enseignement de la littérature prise comme l'incarnation de la culture dans l'enseignement du français langue étrangère.

5 L'intérêt des Français pour la langue turque a commencé bien avant l'intérêt des Turcs pour la langue française. 1669 est la date de la fondation de l'École des jeunes de langues par Colbert qui est l'ancêtre de l'Inalco actuel. L'Empire ottoman avait des relations diplomatiques avec les pays européens depuis sa naissance mais les Ottomans eux-mêmes préféraient apprendre l'arabe et le persan et laissaient les drogmans de la Porte établir les contacts avec les Européens. Parmi les langues utilisées par les drogmans qui appartenaient aux minorités de l'empire, l'italien et surtout le français occupaient une place privilégiée. Au XVIII ${ }^{\mathrm{e}}$ siècle l'Empire ottoman a commencé de perdre des territoires en Europe. En 1774, pour la première fois il a perdu des territoires où vivaient des musulmans. 
6 Cet événement a rendu évident aux yeux des Ottomans la supériorité militaire des ennemis et ils ont ressenti le besoin de rechercher les causes de cette supériorité et donc de s'ouvrir à l'Occident. Ekrem Aksoy (2007) explique pourquoi les Ottomans, à cette époque, ont avantagé le français parmi les autres langues européennes et ce malgré la prédominance militaire et politique de l'Angleterre et de l'Autriche (ibid.). L'éclat culturel de la France de Louis XIV a perduré en Europe tout au long du XVIII ${ }^{\mathrm{e}}$ siècle ; quand les Ottomans ont décidé de s'ouvrir à l'Occident, le français s'est imposé comme une langue de culture dominante. Donc pour apprendre le secret de la prépondérance militaire des Européens, les Ottomans ont fondé des écoles de génie où l'éducation se faisait en grande partie en français : l'École du génie maritime (1775), l'École du génie militaire (1795), l'École de médecine (1827), l'École militaire (1834). C'est ainsi que la langue française a fait son entrée dans l'éducation ottomane.

7 À partir de 1821 la Sublime Porte a décidé d'utiliser des drogmans Turcs pour mener ses affaires étrangères et la Chambre (ou bureau) de traduction de la Sublime Porte (Tercüme odası) a été fondée. On a commencé à envoyer des jeunes gens en Europe pour apprendre les langues européennes et en priorité le français. Ce sont ces jeunes gens qui vont réaliser quelques années plus tard les premières traductions d'œuvres littéraires en turc dont la grande majorité sont des œuvres françaises. La création de la Chambre de traduction est suivie par la période des Tanzimat (1839-1878) c'est-à-dire des restructurations de l'Empire. Cette période de réformes est une ouverture à l'influence de l'Occident et elle se termine avec l'avènement d'un parlement ottoman en 1878.

8 Dans ce court article, nous limitons notre étude au rôle de la culture dans les traductions de la littérature française d'abord et par la suite dans l'enseignement du français langue étrangère.

\section{Les deux bureaux de traduction : une renaissance turque}

9 À l'instar du bureau de traduction de la Sublime Porte instauré en 1821, deux bureaux qui suivent le même modèle sont mis en œuvre par le gouvernement républicain : un premier bureau de traduction fondé par Hasan Ali Yücel, ministre de l'Éducation nationale en 1940 et un deuxième, qui continuera ses travaux après la fin du mandat de Yücel en 1947.

10 Les premières traductions jouent un rôle de guide pour le public ottoman. Ceux qui ne possédaient pas la connaissance d'une langue étrangère, c'est-à-dire la grande majorité des lecteurs découvrent la littérature française grâce aux premières traductions. Cette découverte est non seulement celle d'une œuvre littéraire mais également celle d'une nouvelle culture. Deux recueils ouvrent le pas des traductions : «En 1859 un recueil de textes philosophiques composé de passages de Fontenelle, de Fénelon et de Voltaire (Muhaverat-ı Hekimiye de Münif Paşa) et un recueil de poèmes qui contient des poèmes de Lamartine, de la Fontaine et de Racine (Tercüme-i Manzume de şinasi)» (Etensel Ildem 1997 : 59).

11 Les Aventures de Télémaque de Fénelon est traduit par Yusuf Kâmil Pacha en 1862. Raus (2003: 81) note que «si [...] Télémaque joue [un] rôle essentiel dans la culture occidentale, c'est bien par une stratégie de lecture qui vise la scolarisation de l'élève». 
Cette œuvre qui fut traduite et publiée un grand nombre de fois en Espagne (Viña Molleda \& Fernandez Fraile 2003) dans le but d'enseigner le français, a une valeur pédagogique évidente qui n'a pas échappé à son traducteur Yusuf Kâmil Pacha qui l'a choisie pour présenter la culture française de l'âge classique au public turc. Les traductions suivantes sont Micromégas de Voltaire (1865) et des extraits de l'Émile de Rousseau. Akünal (1985 : II 454), constate que « ceux qui ont fait démarrer le premier mouvement de traduction pour transmettre la culture occidentale à la culture ottomane ont choisi comme contenu de leurs traductions la philosophie occidentale». À partir de 1869, Ahmet Vefik Pacha commence à traduire et à adapter les pièces de Molière. Il a créé une salle de théâtre à Bursa, très fréquentée par la population surtout féminine de la ville. Le traducteur préfère adapter les pièces qui sont adaptables à la culture ottomane; quand une pièce ne se prête pas à l'adaptation, Ahmet Vefik Pacha fait une traduction qui est fidèle au texte de Molière. Ainsi Le Misanthrope est traduit en vers tandis que George Dandin devient Yorgaki Dandini et les événements sont transportés dans la société stambouliote de l'époque.

12 À partir de 1880 , les traductions augmentent considérablement en nombre et elles ne sont plus considérées comme des événements majeurs. Dans la préface de l'anthologie de littérature française parue en 1890 (poésie des poètes romantiques, extraits de $L a$ Dame aux Camélias, textes des philosophes du XVIII siècle etc.), Demir (2007 : 531) cite l'homme d'État Said Bey, lequel souligne l'importance de l'activité de traduction: "C'est un travail fait pour la patrie. On ne peut suivre les développements qui ont lieu en Occident que grâce aux traductions». Les traducteurs, en s'inspirant de leurs traductions, composent les premières œuvres à l'occidentale de la littérature ottomane. Şinasi, traducteur de poésie, écrit la première pièce de théâtre moderne şair Evlenmesi (le mariage du poète) en 1860 et Recaizade Ekrem Efendi, traducteur de Graziella, l'un des premiers romans ottomans : Araba Sevdasl (l'Amour de loin) en 1889.

13 Le rôle attribué à la littérature sera encore plus important dans les années qui vont suivre les réformes de la jeune République de Turquie. Le ministre de l'éducation Hasan Ali Yücel qui a établi le nouveau système d'éducation nationale est l'instigateur de la nouvelle politique de traduction. Dès 1940 un premier bureau est créé au sein même du ministère et pendant plus de deux décennies les meilleurs professionnels du pays, tant écrivains de métier qu'académiciens, vont y traduire un nombre croissant d'ouvrages chaque année. Quand Hasan Ali Yücel finit son mandat en 1946, 496 ouvrages de littérature ont été traduits dont 171 de littérature française. D'autres maisons d'édition publiaient également des ouvrages de traduction. Dans sa thèse de doctorat Cemil Göker (1958 : 23) compte « 1089 ouvrages traduits du français entre 1923 et 1958 ».

Les travaux du deuxième bureau de traduction sont beaucoup plus structurés que ceux du premier. D'après Demir (2007 : 528), Fehmi Ziya Ülgen, le célèbre critique littéraire de la première moitié du $\mathrm{XX}^{\mathrm{e}}$ siècle a souligné l'importance de cet aspect de la traduction : « Il faut que l'activité traduisante obéisse à un système, autrement dit pour que la traduction embrasse l'ensemble de la culture occidentale, il faut qu'elle devienne une institution». Selon le professeur Hasan Anamur (1977: IX): «Les activités du bureau de traduction sont l'aboutissement logique du besoin vital du lecteur turc d'accéder à la pensée et à l'art universels par le truchement de la littérature. C'est une tentative d'ouverture intellectuelle, une tentative de formation littéraire, artistique et psychologique, une sorte de mobilisation intellectuelle». Ces années d'activité traduisante sont à la fois une époque de renaissance, de retour aux sources de la 
littérature gréco-romaine, mais aussi une période de lumières où la philosophie universelle est absorbée par le public turc.

Que ce soit pendant la période des Tanzimat ou pendant les premières années de la République de Turquie, la traduction des œuvres littéraires a été un projet de modernisation et d'ouverture vers l'Occident. Les Ottomans avaient constaté en premier l'avance de l'Occident dans le domaine militaire et technologique mais rapidement ils ont voulu connaître la philosophie, le système intellectuel qui avaient causé cette avancée. Le meilleur moyen de connaître l'Occident était donc de connaître sa littérature ; c'est ce que les Ottomans du Tanzimat et les Turcs de la République ont voulu découvrir. Un développement de la connaissance des langues occidentales devait forcément accompagner cet élan. Nous avons vu que dès le début du XIX ${ }^{\mathrm{e}}$ siècle le français a été enseigné dans la chambre de traduction de la Sublime Porte. L'anglais et l'allemand ont suivi plus tard le français. La chambre de traduction était également chargée de l'éducation linguistique des fonctionnaires de l'empire. L'enseignement du français se faisait en 1851 à travers la littérature française : au niveau débutant/post débutant on étudiait Le Siècle de Louis XIV de Voltaire, au niveau intermédiaire on faisait la lecture des œuvres de Racine. Au niveau élevé, après avoir perfectionné les compétences langagières à l'aide de la littérature, on faisait une lecture orale des articles de presse (Timur Ağildere $2007: 187$ ).

\section{De l'enseignement en français à l'enseignement du français}

Parallèlement aux traductions, l'enseignement du français prend de l'essor dans la deuxième moitié du XIX siècle. Les minorités avaient depuis un certain temps leurs écoles françaises. (1783 Saint-Benoît, 1846 Sainte-Pulchérie, 1856 Notre Dame de Sion, 1886 Saint-Michel, 1870 Saint-Joseph). Le lycée franco-turc de Galatasaray est fondé en 1868. Dans ce lycée l'enseignement se faisait en grande partie en français. Le français fut également introduit dans les écoles secondaires ottomanes à partir de 1869, à côté de l'arabe et du persan. Mehmet Halit Bey, un pédagogue réputé, écrit en 1891 dans un journal d'Istanbul « parmi les nations européennes, la France est celle qui unit le plus le savoir et les sciences. Des œuvres exceptionnelles écrites par des génies littéraires sont une source de fierté pour la France. Une vie ne serait pas suffisante pour lire ces chefs d'œuvres. [...] Quelqu'un qui ne sait pas le français ne peut pas comprendre comme il se doit les œuvres des génies comme Corneille, La Fontaine, Molière et Victor Hugo » (cité par Demiryürek 2013 : 134). Ces paroles de Mehmet Halit Bey explicitent l'importance que les éducateurs ottomans attribuent à la littérature française.

«Le français a été le véhicule le plus notable portant en Turquie la civilisation moderne de la France et de l'Occident ", comme l'affirme Efeoğlu (2014:84), référant à Ömer Seyfettin (1884-1920), le célèbre écrivain nationaliste et francophone du début du XX $\mathrm{X}^{\mathrm{e}}$ siècle, auteur d'une grammaire de la langue française, qui critique cependant les écoles étrangères, françaises et autres d'Istanbul dont les élèves s'éloignent selon lui de leur culture nationale, soulignant le rôle sociopolitique et culturel que le français a joué dans l'Empire ottoman.

$\mathrm{Au}$ Darülmuallimin, l'école normale qui formait les professeurs du secondaire, fondée en 1848 , le français est enseigné aux futurs professeurs dès la première année, « surtout en forme de thème et de version » (Demiryürek 2013 : 131). L'enseignement du français 
se fait dans les lycées ottomans avec une méthode traditionnelle. On imite les méthodes occidentales utilisées dans l'enseignement du latin et du grec ancien. Le but de l'enseignement est de doter les élèves d'un bon niveau de langue (français en l'occurrence) si l'on veut qu'ils profitent selon Fazıl Ahmet Bey (1914) « de l'avantage scientifique des pays européens" (Demiryürek, 2013: 134-135). Jusqu'en 1928 on enseigne le français "pour suivre la littérature internationale, pour apprendre la langue de la politique et de la littérature, pour profiter de l'avancée culturelle de l'Europe etc. » (Demiryürek, $2013: 138$ ).

Après le passage des caractères arabes aux caractères latins, le système éducatif a également subi des transformations: l'école primaire est devenue obligatoire pour tous. L'éducation est devenue laïque et uniforme. L'arabe et le persan ont disparu du système scolaire pour laisser leur place aux langues occidentales parmi lesquelles le français a gardé sa place privilégiée. En 1933 une nouvelle loi universitaire a été promulguée pour encourager la création de nouvelles universités. Le français a commencé à être enseigné dans ces universités. La faculté des lettres de l'Université d'Ankara possède un département de français où l'enseignement a commencé en 1936 et qui a donné ses premiers diplômes en 1940. Dans le programme de ce département la littérature française tenait un rôle important: on insistait sur les compétences linguistiques les deux premières années et sur l'étude de la littérature les deux dernières années (Etensel Ildem 2015). L'université d'Ankara et l'université d'Istanbul étaient les seules universités jusqu'aux années 50 avec l'université de pédagogie de Gazi, à comprendre un département de français. L'agencement des cours somme toute assez traditionnel, n'a pas beaucoup varié (dans le cas de l'université d'Ankara) jusqu'aux années 1960. Pouvoir lire et comprendre les grandes œuvres classiques et modernes et en discuter les idées était le but des études. Les diplômés de ce département pouvaient entrer dans la fonction publique, dans l'enseignement ou encore dans le secteur privé.

\section{La place de la littérature / culture française dans l'enseignement universitaire de nos jours}

Quelle est la place de la littérature française dans les programmes de nos jours ? À l'Université d'Ankara dont les premiers professeurs, notamment Bedrettin Tuncel, ont collaboré activement aux travaux du deuxième bureau de traduction, les cours de littérature avaient, comme nous l'avons remarqué, une place importante. De nos jours, le détail des cours a peut-être varié mais le principe est resté le même. Si nous comparons le programme des départements de français de quatre universités (Ankara ${ }^{1}$, Istanbul ${ }^{2}$, Hacettepe $^{3}$ et Selçuk ${ }^{4}$ ) nous voyons que le principe reste le même : apprendre la langue et étudier la littérature. Des cours d'histoire littéraire sont au programme de toutes ces universités du Moyen Âge jusqu'au XXe siècle. Ces cours d'histoire littéraire complètent et/ou encadrent les cours de textes littéraires répartis également en siècles. La culture française est expliquée à travers sa littérature. Le programme de l'Université Namık Kemal ${ }^{5}$ qui a été fondée en 2006 a introduit une grande nouveauté : des cours intensifs d'une autre langue étrangère, l'allemand, l'anglais ou le japonais chaque année. La littérature de cette deuxième langue n'est pas enseignée. Les étudiants terminent leurs études de français avec l'acquisition d'une deuxième langue étrangère et la grande majorité d'entre eux choisissent le japonais. 
21 Prenant en considération tous les cours de littérature et d'histoire littéraire qui sont au programme de la majorité des départements de français on peut toutefois se demander si la littérature française représente encore la culture à l'ère de la technologie et d'internet. Selon Muammer Nurlu (2013) qui est l'auteur d'un ouvrage intitulé L'enseignement $d u$ turc en France, les programmes des départements de langue et littérature françaises des universités turques ne remplissent pas leur fonction. «Si leur fonction est d'enseigner la langue française, un programme de neuf mois concentré sur la langue seulement serait suffisant. Si leur but est de refléter les développements sociaux, culturels et politiques de la France, ils ne le réalisent pas» (Nurlu 2013 : 494). Nurlu compare le programme de l'Inalco avec ceux des départements de français des universités turques. Il constate qu'à l'Inalco les cours sont plus centrés sur la culture turque et qu'ils ont une approche plus politique. «En fait l'État français, quand il enseigne la langue et la culture turques, vise à pourvoir à ses propres besoins et met en place un point de vue propre à la France» (Nurlu 2013: 479). Nurlu donne comme exemple les cours d'histoire ottomane, les cours sur l'Islam et le monde turcophone (les républiques turcophones d'Asie centrale), les relations entre la Russie et les républiques turcophones d'Asie centrale etc. La connaissance de la langue turque sert à aborder la situation politico-sociale de la région. Nurlu suggère une approche similaire pour les études françaises en Turquie. La connaissance de tous les siècles de littérature française ne sert pas selon lui à enrichir l'horizon des étudiants turcs.

Pour conclure nous dirons que la littérature française a été un instrument d'occidentalisation et de modernisation. Dans un premier temps les traductions des œuvres littéraires ont ouvert la voie à la connaissance de la littérature française. Dans un deuxième temps l'enseignement du français dans les universités a donné un accès direct aux œuvres en question. Ce mouvement a commencé pendant le Tanzimat et a continué pendant les premières décennies de la République. Mais à notre époque de mondialisation, avec les nouvelles techniques de communication, avec internet et Wikipedia la littérature française peut-elle continuer à remplir son rôle de projet culturel en Turquie et dans le monde ou faut-il songer à désacraliser la littérature ? Cette question nous semble digne de réflexion.

\section{BIBLIOGRAPHIE}

AKSOY Ekrem (2007). « La francophonie en Turquie de l'Empire à nos jours ». Documents pour l'histoire du français langue étrangère ou seconde 38-39, 57-66.

AKÜNAL, Dündar (1985). « Çevriri ve Batılılışma » (Traduction et occidentalisation). In Murat Belge (dir.). Tanzimat'tan Cumhuriyet'e Türkiye Ansiklopedisi. Istanbul : İletişim Yayınları, II 452-454.

ANAMUR, Hasan (1997). « Préface ». In Hasan Anamur (dir.). La Traduction : Carrefour des cultures et des temps. Istanbul : Université technique de Yildiz, 1997, IX-XV.

DEMIR, Nurmelek (2007). «L'importance de la traduction dans la Turquie du XIX ${ }^{\mathrm{e}}$ siècle et un recueil de morceaux choisis des œuvres littéraires françaises traduites en turc ». Frankofoni, 19. 
DEMIRYÜREK,Mehmet (2013). « Türkiye'de Yabancı Dil Olarak Fransızca Öğretiminin Tarihi Gelişimi Üzerine bir Değerlendirme (1891-1928)» (Une évaluation du développement historique de l'enseignement du FLE en Turquie). Hacettepe Eğitim Fakültesi Dergisi, n²8, 130-140. En ligne :

[http://www.efdergi.hacettepe.edu.tr/makale_goster.php?id=132].

EFEOĞLU, Ertuğrul (2014). « Les témoignages d'Ömer Seyfettin portés sur l'enseignement du français langue étrangère dans les écoles d'Istanbul au début du XX $\mathrm{X}^{\mathrm{e}}$ siècle ». Documents pour l'histoire du français langue étrangère ou seconde, 52, 83-90.

ETENSEL ILDEM, Arzu (1997). «Les traductions littéraires du français en turc : aperçu historique et tendances actuelles ». In Hasan Anamur (dir.). La Traduction : Carrefour des cultures et des temps. Istanbul : Université technique de Yildiz, 1997, 59-66.

ETENSEL ILDEM, Arzu (2015). « La formation des enseignants de français en Turquie : le cas du département de français de l'Université d'Ankara ». Documents pour l'histoire du français langue étrangère ou seconde, 55, 137-148.

GÖKER, Cemil (1958). Recherches bibliographiques sur les traductions du français en turc depuis la République 1923-1958. (Thèse non publiée). Ankara : Université d'Ankara DTCF.

NURLU, Muammer (2013). « Fransa'da Türkçe öğretimi, Türkiye'de Fransızca öğretimi » (L'enseignement du turc en France, l'enseignement du français en Turquie). Turkish Studies, 8/10, 477- 498. En ligne : [Fransa'da Türkçe öğretimi, Türkiye'de Fransızca öğretimi].

RAUS, Rachele (2003). «Stratégies de lecture \& de pédagogie : le cas de la sagesse dans Télémaque ». Documents pour l'histoire du français langue étrangère ou seconde, 30, 72- 83.

TIMUR AĞILDERE, Suna (2007). « Les Élites de la Sublime Porte ou les médiateurs francophones du bureau de traduction au XIX ${ }^{\mathrm{e}}$ siècle ». Documents pour l'histoire du français langue étrangère ou seconde, 38-39, 183-191.

VIÑA MOLLEDA, Maria Elena \& FERNANDEZ FRAILE, Eugenia (2003). « Les Aventures de Télémaque dans l'enseignement du français langue étrangère en Espagne ». Documents pour l'histoire du français langue étrangère ou seconde, 31, 117-132.

\section{NOTES}

1. Cf. [www.dtcf.ankara.edu.tr/bati-dilleri-ve-edebiyatlari/fransiz-dili-ve-edebiyati-anabilimdali].

2. $C f$. [edebiyat.istanbul.edu.tr/?p=9366].

3. $C f$. [www.hafde.hacettepe.edu.tr/fdeLisansProgrami].

4. $C f$. [www.selcuk.edu.tr/edebiyat/fransiz_dili_ve_edebiyati/bolum_dersleri/tr].

5. $C f$. [fened-fde.web.nku.edu.tr/DersKatalog/0/s/3749/3783]. 


\section{RÉSUMÉS}

La langue et la culture françaises ont joué un rôle très important lors de l'ouverture de l'Empire ottoman aux influences étrangères et occidentales. Le français a été la première langue occidentale enseignée dans l'Empire. Les Ottomans ont appris la culture française à travers les traductions des œuvres littéraires françaises. Le premier bureau de traduction durant la période $\mathrm{du}$ Tanzimat et le deuxième mouvement de traduction dans les premières années de la république avaient pour mission de faire connaître la culture à travers la littérature. Les œuvres littéraires françaises (et européennes) étaient les instruments de l'apprentissage du français dans les programmes scolaires. De nos jours la place que joue la littérature dans l'enseignement universitaire $\mathrm{du}$ français reste importante. Les cours d'histoire littéraire figurent dans le programme de presque tous les départements de français. N'est-il pas temps de changer cette situation?

French language and culture played a very important role in the opening of the Ottoman Empire to foreign and Western influences. French was the first Western language taught in the Empire. The Ottomans learned French culture through translations of French literary works. The first translation office during the Tanzimat period and the second translation movement in the first years of the republic had the mission of making culture known through literature. French (and European) literary works were the instruments for learning French in school curricula. Nowadays the place that literature plays in teaching French in university education remains important. Literary history courses are included in the curriculum of almost all French departments. Isn't it time to change this situation?

INDEX

Keywords : French as foreign language, French literature, French culture, Turkish as a foreign language, Inalco

Mots-clés : enseignement du FLE, littérature française, culture française, enseignement du turc, Inalco

\section{AUTEUR}

\section{ARZU ETENSEL ILDEM}

Université d'Ankara - ildem@ankara.edu.tr 